\title{
AREA-WIDE MANAGEMENT OF FRUIT FLIES IN A TROPICAL MANGO GROWING AREA INTEGRATING THE STERILE INSECT TECHNIQUE AND BIOLOGICAL CONTROL: FROM A RESEARCH TO AN OPERATIONAL PROGRAMME
}

\author{
P. LIEDO ${ }^{1}$, P. MONTOYA ${ }^{2}$ AND J. TOLEDO ${ }^{1}$ \\ ${ }^{1}$ El Colegio de la Frontera Sur, Tapachula, Chiapas, México; pliedo@ecosur.mx \\ ${ }^{2}$ Programa Moscafrut, SAGARPA-IICA, Metapa, Chiapas, México
}

\begin{abstract}
SUMMARY
The Sterile Insect Technique (SIT) has been successfully used for the control of fruit flies in a number of places in the world. One requirement for its successful application is that wild populations should be at low densities to achieve effective sterile to wild fly overflooding ratios. This has been an important reason that has limited its integration in fruit fly management in tropical fruit growing areas, where climate conditions and the availability of hosts all year-round results in high population densities. Here we report the results of a project where SIT integration into fruit fly management was evaluated under the tropical conditions of the mango growing area in the Soconusco region of Chiapas, Mexico. The basis for the area-wide integrated pest management (AW-IPM) approach was the knowledge of the population dynamics of the pest fruit flies in the region and of the fruit phenology. The main commercial mango growing areas are in the lowlands, where fruit fly populations are very low outside of the mango production season. Population densities are higher in the midlands and highlands, where alternate hosts are common in backyards and as part of the natural vegetation. We call these refuge areas, and the AW-IPM approach aimed at establishing a biological barrier with releases of parasitoids and sterile male fruit flies to suppress the fruit fly populations and prevent or minimize the dispersal of wild flies from the refuge areas to the mango orchards. In 2014, after two years of releases, fruit fly population densities were suppressed more than $70 \%$ in the release area and $65 \%$ in the entire area, including the lowlands with the mango orchards. With the support of fruit growers, state and federal governments, this project was continued and established as an operational AW-IPM programme. In 2016, after 4 years of programme implementation, the detection of wild flies was significantly reduced, and the number of batches of fruit that were rejected at the packing houses due to the detection of infested fruits was the lowest in the past 12 years, since the recording of these data was initiated. These indicators declined even further in 2017. The results obtained demonstrate that AW-IPM integrating the SIT can be applied successfully against fruit flies under tropical conditions with naturally high pest densities, providing there is adequate knowledge on the population dynamics of the fruit fly species present in the region.
\end{abstract}

J. Hendrichs, R. Pereira and M. J. B. Vreysen (eds.), Area-Wide Integrated Pest Management: Development and Field Application, pp. 197-214. CRC Press, Boca Raton, Florida, USA. (C) 2021 IAEA 
Key Words: Integrated pest management, autocidal control, SIT, augmentative biological control, Anastrepha fruit flies, Tephritidae, Anastrepha ludens, Anastrepha obliqua, Diachasmimorpha longicaudata, Soconusco, Chiapas, Mexico

\section{INTRODUCTION}

In Mexico, mango represents one of the most important fruit production and export value chains, with more than 180000 ha of cultivation, giving an annual production of approximately 1.8 million tons. Mexico ranks $6^{\text {th }}$ by area and $4^{\text {th }}$ by production in the world, and on the international market Mexico and India are among the most important exporting countries by volume (SIAP 2015).

Among the factors that limit or affect mango production and marketing are insect pests, and within these, fruit flies are among the most devastating. In view of their importance, these are considered of public interest and for this reason the National Campaign against Fruit Flies was established in 1992. The Campaign has succeeded in achieving fruit fly pest free areas (FF-PFA, FAO 2016) in 52.8\% of the national territory, and fruit fly areas of low pest prevalence (FF-ALPP, FAO 2008) in another $10.4 \%$, while the remaining $36.8 \%$ is considered a zone under phytosanitary management (Liedo 2016; Ramírez y Ramírez et al. 2019). Due to their agroecological requirements, mango producing areas are located mostly in the subtropical and tropical zones of the country, most of which are in the area under phytosanitary management. Under these favourable ecological conditions that promote fruit fly abundance, the development of technologies and the design of pest management strategies are required to allow the production of fruits free of fruit fly damage.

There are modern and appropriate and more sustainable technologies to deal with these pests, such as the Augmentative Biological Control (ABC) and the Sterile Insect Technique (SIT), among others (Montoya and Toledo 2010; Enkerlin et al. 2021). These technologies, integrated with other control methods have been applied successfully in Mexico to prevent for over 35 years the invasion of the Mediterranean fruit fly, Ceratitis capitata (Wiedemann), into southern Mexico along the border with Guatemala (Enkerlin et al. 2015) and for the implementation of FF-PFA for native Anastrepha fruit flies in the north of the country (Reyes et al. 2000; Liedo 2016). However, under the tropical conditions in which commercial mango is extensively grown, native Anastrepha fruit flies have high rates of population growth and therefore the effective application of these technologies is much more challenging (Montoya et al. 2000).

The characteristics of the SIT and the ABC, as well as the high mobility of fruit flies, make it necessary to adopt an area-wide integrated pest management (AW-IPM) approach, which considers the management of the total population of the pest and its spatial distribution (Hendrichs et al. 2007; Montoya et al. 2007).

In the mango producing region of Soconusco, Chiapas in southern Mexico, there is ample knowledge about the population dynamics of Anastrepha fruit flies (Aluja et al. 1996; Celedonio-Hurtado et al. 1995; Montoya et al. 2000). In the case of Anastrepha ludens (Loew) and Anastrepha obliqua (Macquart), which are the species that infest mango, it is known that their populations are high in the midlands and in the highlands (120-600 m elevation) with little temporal fluctuations. 
In the commercial mango production areas of the lowlands (0-120 m elevation), the Anastrepha populations are low most of the year and only increase during the mango fruiting season, when growers have to apply repeated ground bait sprays to minimize fruit fly infestation.

Based on the available background information, and with the objective to reduce the bait sprays and fruit fly infestation in mangoes, a project was submitted to validate the use of the ABC and the SIT as elements of an AW-IPM approach, for the management of these native fruit flies in mango. We proposed to carry out this project in the Soconusco region in Chiapas State, considering the available knowledge on fruit fly populations, their hosts and their seasonality, and taking advantage of the infrastructure of the National Fruit Fly Campaign (Mexican Plant Protection Organization SENASICA, and IICA) in the region with respect to mass-rearing and release of sterile fruit flies and parasitoids. This 4 -year project was funded by the National Council of Science and Technology (CONACYT) and the Ministry of Agriculture (SAGARPA) sectorial fund. In view of the increasing support and interest of the mango growers, the project was converted into an operational programme during the fourth and last year of the project.

\section{MATERIALS AND METHODS}

\subsection{Strategy}

It was assumed that the Anastrepha populations are maintained by year-round host availability in the refuge sites of the midlands and highlands outside the mango season. Thus, the designed strategy consisted of implementing a "biological barrier" based on the release of sterile flies and parasitoids in the intermediate zone between the high and the lowlands (ca. 100-200 m elevation), seeking to suppress the populations there and avoiding or minimizing their movement to the lowlands, where most of the commercial mango orchards are located. To facilitate achieving favourable sterile to fertile male ratios, releases of sterile insects were initiated at the end of November or early December 2012 and continued to 2015, i.e. the period when historically the lowest population levels have been observed (Aluja et al. 1996).

In the first year of the project (2011-2012), two trapping transects were established from the highlands to the lowlands, to monitor the populations of fruit flies along an altitudinal gradient (Fig. 1). Before initiating the releases in the second year, a third trapping route was established with the objective of monitoring the populations of sterile flies in the release polygon and adjacent areas.

The initial experimental design for the 4-year project (2011-2015) was: (a) to monitor populations during the first year without the application of the $\mathrm{ABC}$ and the SIT, (b) to apply the ABC and the SIT in the intermediate zone during the second and third years, and (c) depending on results, to transfer the technology to mango growers during the fourth year. Based on the results obtained during the second and third years, when the control methods were applied on an area-wide basis, it was decided to continue with the releases for another year. During this fourth year, the technology was transferred, and from week 10 of 2015, the fruit growers' union was in charge of 
funding and coordinating the parasitoid and sterile fruit fly releases through the Local Board of Plant Health and the State Committee of Plant Health of Chiapas. During this fourth year, the research project was converted into an operational action programme, recognized by the National Fruit Fly Campaign.

Based on the monitoring of the first year and the availability of biological material, a 15000 ha polygon $(21.0 \times 7.14 \mathrm{~km})$ was established for the release of parasitoids and sterile fruit flies. This polygon was located between the cities of Mazatán and Tapachula, in the transition zone between the high and the lowlands. The location of the release polygon and the traps deployed are shown in Fig. 1.

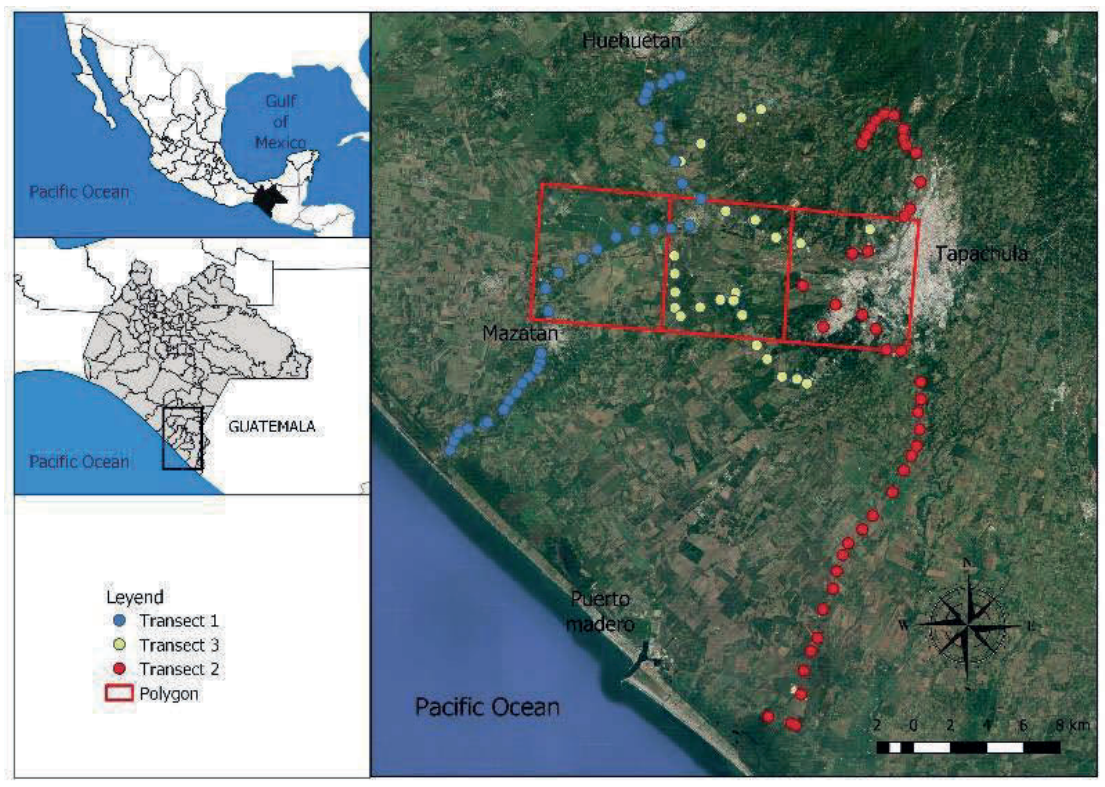

Figure 1. Location of the sterile fly release polygon in the Soconusco region of the state of Chiapas, covering $15000 \mathrm{ha}$, and the three subquadrants for the release and assessment of parasitoids of 5000 ha each, as well as the location of the traps for population monitoring.

The blue dots indicate the location of the traps deployed along transect 1, the red dots correspond to transect 2, and the yellow dots to transect 3 .

For the evaluation of the $\mathrm{ABC}$, the polygon was subdivided into 3 quadrants of 5000 ha each in which to make and assess the release of parasitoids. Initially, it was planned to release the parasitoids only in the sub-quadrant to the East -the one with higher trap captures- and leave the central one as the buffer area and the one on the West as a control, with the intention of alternating the quadrants in the third year and thus be able to make comparisons in time and space. However, based on the results obtained in the second year, it was decided to repeat the release area in the third year (East quadrant) in order to evaluate the effect of the modifications in the release method (see below) and also to contribute to the suppression of pest populations in the area of highest infestation. 


\subsection{Monitoring of Populations}

For the monitoring of the Anastrepha populations, Multilure ${ }^{\circledR}$ traps baited with Biolure ${ }^{\circledR}$ (ammonium acetate + putrescine) were used. Propylene glycol was used for the retention and conservation of the trapped specimen. The traps were checked weekly and the trapped flies identified by species and sex. In the case of $A$. ludens and A. obliqua, the dye marking used for the sterile flies was used to discriminate between the released sterile and wild flies. Along transect 1, 35 traps were deployed from the town of Huehuetán in the highlands to Barra de San Simón in the lowlands. Fortyfour traps were deployed along transect 2 from Canton Pumpuapa to the northwest of the city of Tapachula, in the highlands, to the Ejido Conquista Campesina, in the lowlands. Transect 3 contained 30 traps of which 15 were deployed within the release polygon, 10 were located in the area adjacent to the north of the polygon and another 5 to the south of it (Fig. 1).

\subsection{Biological Material}

Every week, the project received 7.5-8.5 million sterile males of $A$. ludens Tapachula7 genetic sexing strain, 5-10 million sterile males and females of A. obliqua, as well as 5 million of the parasitoid Diachasmimorpha longicaudata (Ashmead). With these quantities and based on the experience of the National Campaign, the target release densities were 533 male $A$. ludens / ha, 333 male A. obliqua / ha, and 1000 parasitoids / ha. The weekly amounts varied slightly depending on the weekly production of the Moscafrut facility in Metapa, as well as the needs of the National Campaign. For some time during the second year of releases, batches of the bisexual A. ludens strain (males and females) were also received, increasing the number of sterile insects released. The opposite was true for A. obliqua as the needs of the National Campaign resulted in smaller quantities being received sometimes (see Table 1 and Fig. 4), reducing the release densities.

Table 1. Number of sterile flies received during three release seasons

\begin{tabular}{|l|r|r|r|}
\hline & $2012-13$ & $2013-14$ & \multicolumn{1}{|c|}{$2014-15^{*}$} \\
\hline A. ludens Tap-7 males & & & \\
\hline Total & 499771956 & 436226000 & 269320000 \\
\hline Average / week & 9610999 & 8388961 & 9974815 \\
\hline A. ludens bisexual & & & \\
\hline Total & 85729000 & 517932000 & 241365000 \\
\hline Average / week & 1617528 & 9772302 & 7785968 \\
\hline A. ludens sum of males & & & \\
\hline Total & 542636456 & 695192000 & 390002500 \\
\hline Average /week & 10419763 & 13275112 & 13867799 \\
\hline A. obliqua & & & \\
\hline Total & & & 244436000 \\
\hline Average / week & 8879868 & 9520302 & 8147867 \\
\hline
\end{tabular}

* In the 2014-15 season, data are included only until week 22 (June 6, 2015) 
During the three release seasons, a total of 1205 million sterile A. ludens Tap-7 strain (only males), 845 million sterile $A$. ludens bisexual strain (males and females), 1219 million sterile $A$. obliqua (males and females) and 385 million $D$. longicaudata parasitoids were released. The number of sterile flies received in each of the three release seasons, as well as weekly averages, are shown in Table 1.

The quality of these sterile insects is shown in Table 2. From the series of quality control tests that were applied, we selected the percentage of flying flies after chilling as a parameter representing quality of this biological material. In the quality control manual this test is known as "absolute-post-chill flyers" (FAO/IAEA/USDA 2019).

Table 2. Quality of the sterile flies received during three release seasons, as percentage of flying flies after chilling

\begin{tabular}{|l|r|r|r|}
\hline \multicolumn{1}{|c|}{ Strain } & 2012-13 & 2013-14 & $2014-15^{*}$ \\
\hline A. ludens Tap-7 & 81.05 & 86.14 & 85.42 \\
\hline A. ludens bisexual & 87.47 & 89.05 & 85.23 \\
\hline A. obliqua & 88.46 & 89.39 & 88.26 \\
\hline
\end{tabular}

*For the 2014-15 season, data are included only until week 22 (June 6, 2015)

The mass-production facility in Metapa delivered the biological material to the Mediterranean Fruit Fly Emergence and Release Facility (CEMM by its initials in Spanish), located near the Tapachula airport. All biological material was received as irradiated pupae under hypoxic conditions. The CEMM staff placed the pupae in "Mexico" type emergence towers that were provided with water and food. The food was a mixture of sugar and enzymatic hydrolysed yeast in a 24:1 ratio. The towers were kept in the emergence rooms at $23 \pm 1{ }^{\circ} \mathrm{C}$ and $65 \pm 5 \%$ relative humidity. Adults emerged 2-3 days later and were released once they were sexually mature, i.e. 5 days later in the case of $A$. ludens and 4 days in the case of $A$. obliqua. On the release day, the towers were placed in a cold room at $2-4{ }^{\circ} \mathrm{C}$ for one hour to immobilize the adults, and then they were placed in specially designed refrigeration boxes and transported to the airport for chilled aerial release (Hernández et al. 2010). Images of the emergence towers and the release box are shown in Fig. 2.

The services of the Mubarqui ${ }^{\circledR}$ company were contracted to implement the aerial releases of the sterile flies. This company has adapted aircrafts, appropriate release machines, and support infrastructure to implement these releases. For each release flight, a report was generated indicating the time of the flight, the route followed, the number of sterile insects released and the corresponding density. Samples were taken from each batch of sterile insects to assess standardized quality parameters (FAO/IAEA/USDA 2019).

Parasitoids were released from the ground with the support of the staff and vehicles of the State Committee for Plant Health. During the first year of releases, the parasitized pupae were placed in PARC ${ }^{\circledR}$ boxes (Plastic Aerial Release Container) with a mixture of honey and paper as a food source (Fig. 3A). 


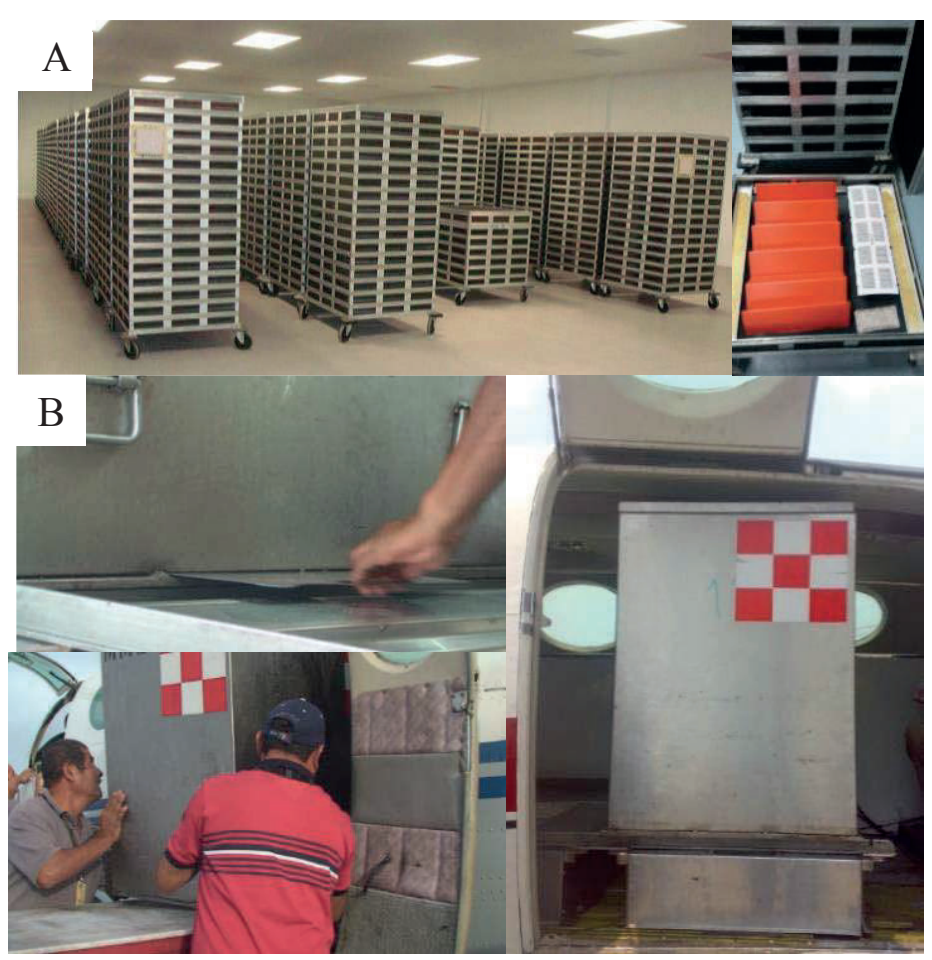

Figure 2. Towers type "México" used for the emergence of sterile adults (A) and chilled release box being loaded into the aircraft $(B)$.

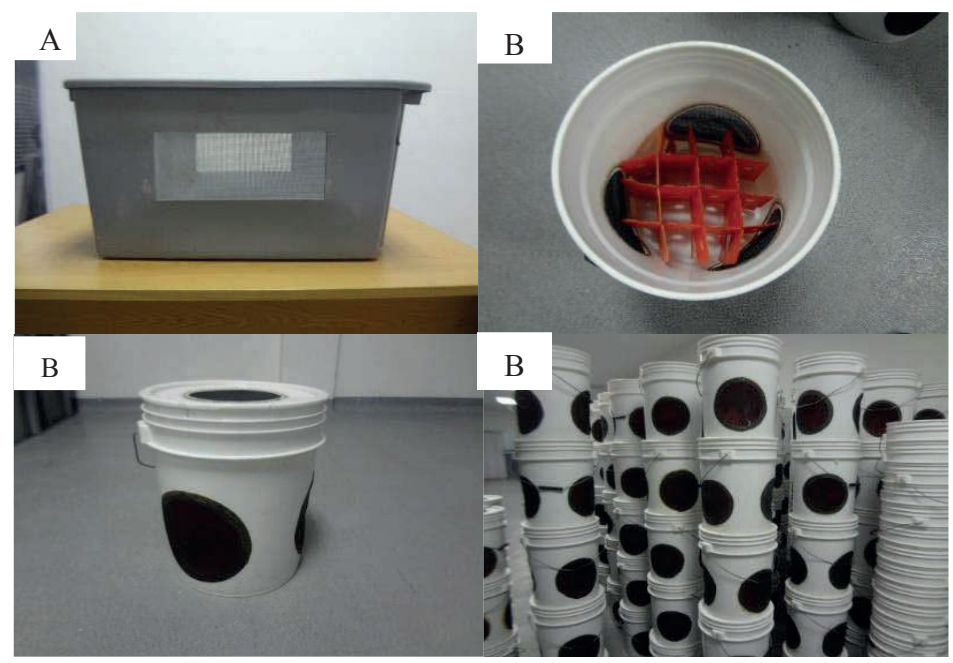

Figure 3. PARC box (A) and "R2D2" devices (B) used for the emergence and feeding of parasitoids and their subsequent ground release in the field. 
After eight days, the emerged parasitoid adults were released. With the aim of improving the performance of these parasitoids, in the following year the release was implemented using "R2D2" devices, which are 20 litres plastic containers with mesh windows on the wall and cover. To increase the surface area, a corrugated plastic honeycomb was placed inside the containers. Each device contained approximately 2000 parasitized pupae (Montoya et al. 2012). The "R2D2" devices are shown in Fig. $3 \mathrm{~B}$. These "R2D2" devices replaced the PARC boxes in the second and third release years.

\section{RESULTS}

\subsection{Biological Material}

Weekly variations in the number of sterile males released during the three release seasons are shown in Fig. 4.

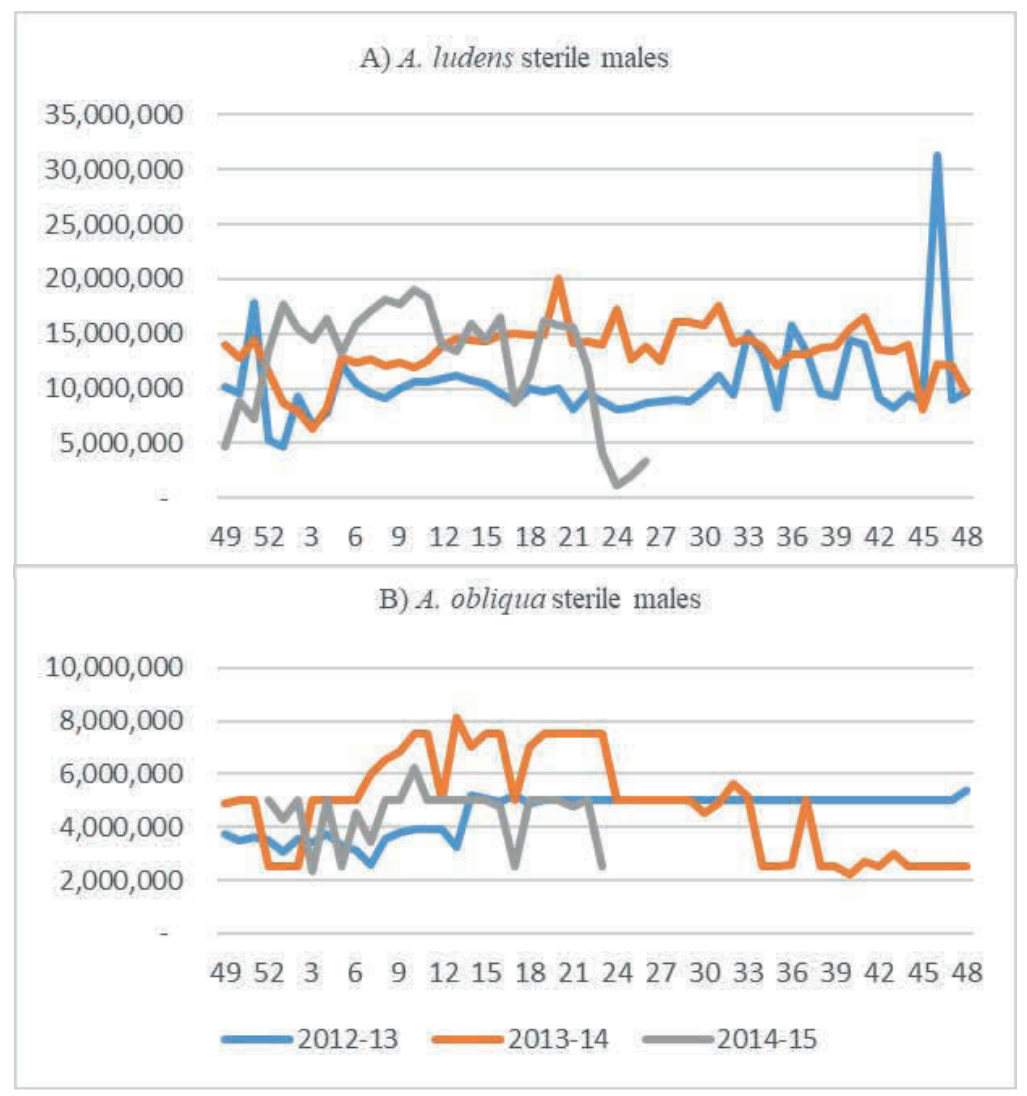

Figure 4. Number of sterile males released per week in each of the three release seasons.

A) A. ludens males of the Tapachula-7 and bisexual strains. B) A. obliqua males. Season 2012-13 is shown in blue, 2013-14 in orange, and 2014-15 in grey. 
For the third season (2014-15), data are shown only up to week 22 when, based on the number and locations of wild fly detections, it was decided to modify the release polygon (see Section 4). It should be noted that since week 10 of this last season, the association of fruit growers took over the funding and coordinating of field activities, fulfilling the goal of technology transfer, and thus transforming a research project into an operational programme.

The number of $A$. ludens sterile males released ranged between 10 and 20 million per week for most of the time for the three release seasons. Numbers for the 2013-14 and 2014-15 seasons were consistently higher. With these quantities, the average densities released were 696, 891 and 849 males per ha for the seasons 2012-13, 201314, and 2014-15, respectively. The highest density was 2084 males / ha in week 46 of 2013 and the lowest was 314 males / ha in week 1 of 2013. Considering the natural population dynamics of this species, in the first weeks of the calendar year it is key to have high sterile fly densities in the field, which was achieved in the 2014-15 season.

For A. obliqua the quantities of sterile flies were smaller and the variation greater. The average densities released were 302, 323 and 299 males / ha for the seasons 201213, 2013-14, and 2014-15, respectively. The highest density was 543 males / ha in week 13 of 2014 and the lowest was 148 males / ha in week 40 of the same year.

As of week 34 of 2014, there was a significant reduction in A. obliqua sterile fly availability and from week 49 to 52 of 2014 no biological material was received. This was attributed to production problems at the Moscafrut facility and due to the demand for this species by the National Campaign.

\subsection{Sterile Fly Densities}

The releases of sterile flies were monitored with Multilure traps deployed inside the area of the release polygon. Out of the total of 109 traps were deployed as part of the three trapping transects, 30 were located inside this polygon. Average fly per trap per day (FTD) values for trapped sterile males in these 30 traps for each season and species are shown in Table 3.

Table 3. Average of sterile males captured per trap per day (FTD) in the release polygon in each of the three release seasons for $\mathrm{A}$. ludens and A. obliqua

\begin{tabular}{|l|r|r|}
\hline Season & A. ludens & A. obliqua \\
\hline $2012-13$ & 0.766 & 0.643 \\
\hline $2013-14$ & 1.363 & 0.531 \\
\hline $2014-15^{*}$ & 0.472 & 0.135 \\
\hline
\end{tabular}

* Only until week 22, since the release polygon was modified afterwards 
Another parameter used to monitor sterile fly releases was the percentage of traps that trapped sterile flies, regardless of the amount captured. This parameter informs about the uniformity of the releases. Fig. 5 shows how this percentage varied throughout the year for the two species in the three seasons. The average percentage of traps that trapped sterile flies in each season ranged from 53 to $66 \%$ for $A$. ludens and 27 to $60 \%$ for $A$. obliqua. The lower value in A. obliqua corresponded to the $2014-$ 15 season and was related to the suspension of releases from week 49 to 52 due to lack of biological material.

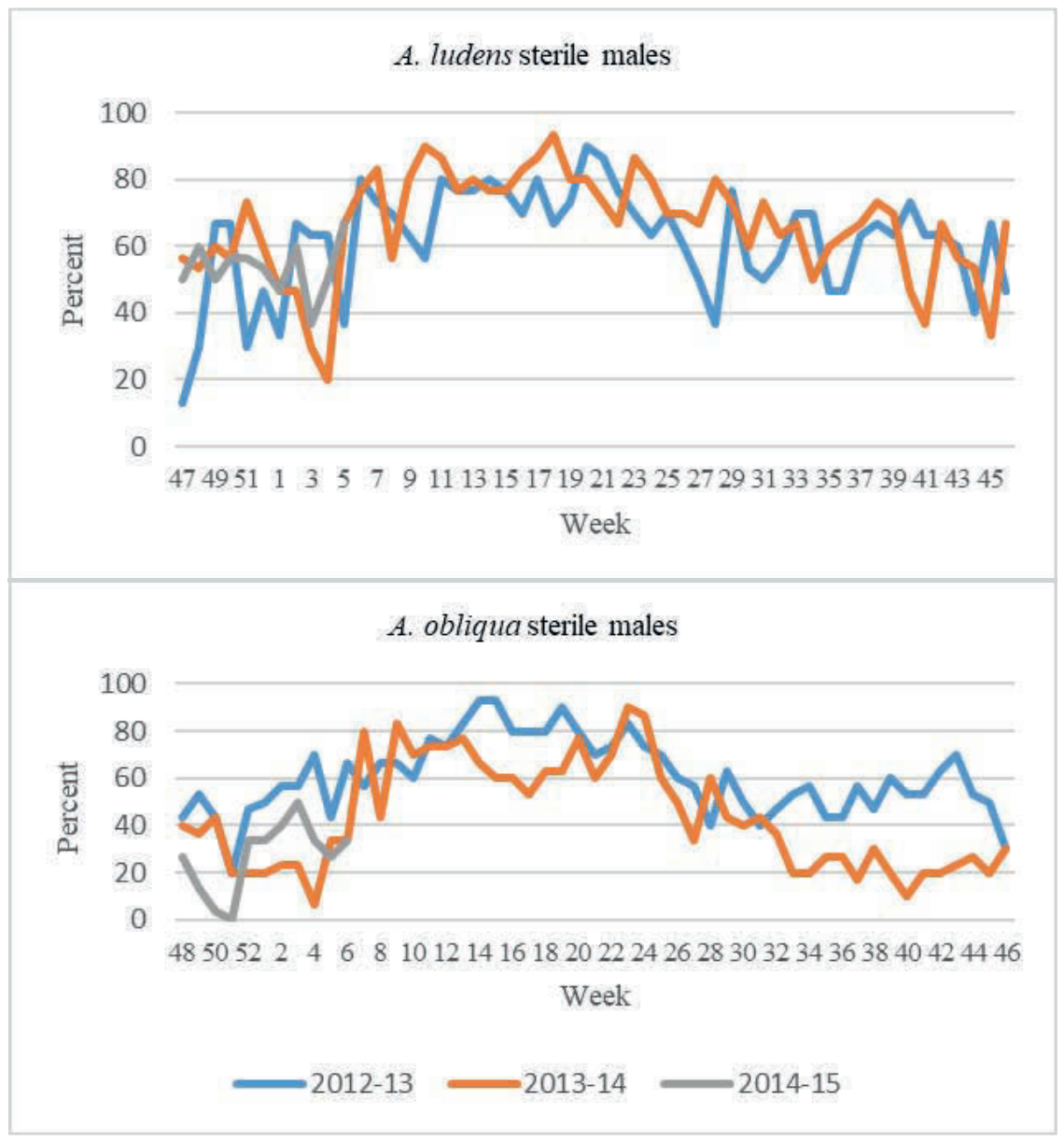

Figure 5. Percentage of traps with capture of sterile flies in each of the three release seasons for A. ludens and A. obliqua.

The sterile: fertile ratio refers to the number of sterile males compared to the number of fertile or wild males in the monitoring traps. This relationship is the basis of the Knipling model (Knipling 1955), which in turn is the foundation of SIT 
application. The ratios achieved for each species and in each season are shown in Table 4. In the case of $A$. ludens, considering the total catches throughout the complete season, the sterile: fertile ratios were always higher than 200:1 and in the 2013-14 season the ratio was 519:1. In A. obliqua these ratios were much lower, even in those cases where the number of sterile males trapped was similar to A. ludens (i.e. season 2012-13).

Table 4. Number of sterile and fertile or wild males captured in traps and the corresponding sterile: fertile ratio for $\mathrm{A}$. ludens and $\mathrm{A}$. obliqua in the three seasons

\begin{tabular}{|l|r|c|l|c|c|c|}
\hline Season & \multicolumn{3}{|c|}{ A. ludens } & \multicolumn{3}{c|}{ A. obliqua } \\
\hline & Sterile & Fertile & S:F & Sterile & Fertile & S:F \\
\hline $2012-13$ & 7936 & 31 & 256 & 6956 & 618 & 11 \\
\hline $2013-14$ & 15058 & 29 & 519 & 5929 & 145 & 41 \\
\hline $2014-15^{*}$ & 2131 & 10 & 213 & 575 & 25 & 25 \\
\hline
\end{tabular}

* Only includes the first 22 weeks, since the release polygon was modified afterwards

Empirical evidence indicates that to obtain good suppression, the sterile: fertile ratio must be greater than 30:1, but ideally greater than 100:1 (Flores et al. 2014, 2017). The achieved sterile: fertile ratios were satisfactory in the case of $A$. ludens, particularly in the 2013-14 season, when the average release density was 891 males / ha. While in the case of $A$. obliqua, the lower release densities (averages $<350$ males / ha) together with the larger wild populations resulted in sterile: fertile ratios much lower than the target of 100:1.

\subsection{Wild Population Densities}

To make an estimate of wild population levels we used wild female catches. During the four monitoring seasons, considering all the traps, a total of $3792 \mathrm{~A}$. ludens and 37445 A. obliqua females were trapped. This represents a 9.8 times greater catch for A. obliqua. To assess the effect of the sterile fly releases, only the traps located in the release polygon were considered (Fig. 6).

The wild populations in the first 2012-13 season were higher in the release polygon than in the preceding year without them. In the subsequent 2013-14 and 2014-15 seasons, the density of sterile flies was increased, and this situation was reversed. The populations were significantly suppressed. The suppression effect ranged from $76-$ $81 \%$ for $A$. ludens, while for A. obliqua, despite the low sterile: fertile ratio, suppression ranged from 89 to $91 \%$. The suppression is confirmed by a comparison of the mean numbers of females per trap per two seasons between the release polygon and the traps located at the north of the polygon (Fig. 7), where no control measures were applied, and south of the polygon, where most commercial mango orchards are located and which was the protected area. 


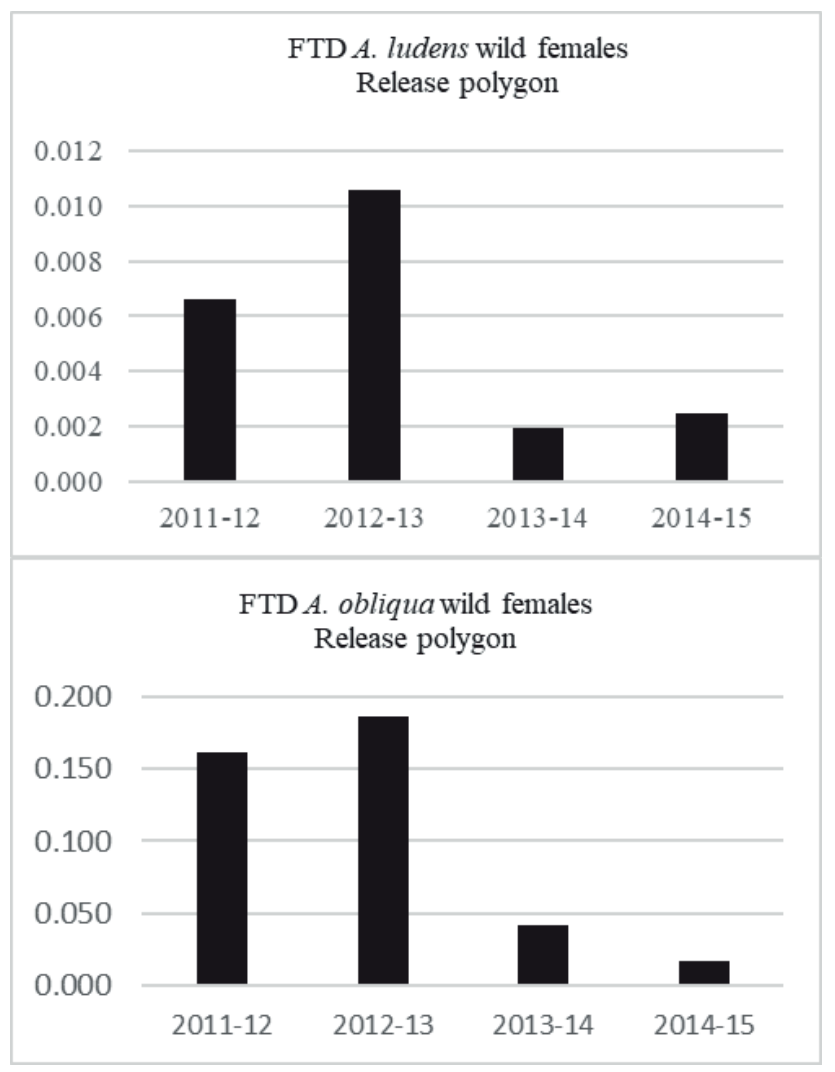

Figure 6. Capture of wild females, expressed in FTD (flies per trap per day), for A. ludens and A. obliqua during four seasons in the release polygon. The 2011-12 season without and the other three seasons with $A B C$ and SIT releases.

Releases of $D$. longicaudata parasitoids resulted in a significant increase in the parasitisation rate. Table 5 shows these rates in the area of the polygon where parasitoids were released and in the control area where no releases were made. Parasitism by $D$. longicaudata in the area where releases were made was $15.12 \%$; the other $1.38 \%$ was by native parasitoids. Montoya et al. (2017) provide more detailed information on the effects of the $D$. longicaudata releases.

Table 5. Number of flies, parasitoids and parasitisation rate in the zone with augmentative releases of $\mathrm{D}$. longicaudata and the control zone without releases

\begin{tabular}{|l|c|c|c|c|}
\hline \multicolumn{1}{|c|}{ Zone } & Flies & Parasitoids & $\begin{array}{c}\text { Parasitism } \\
(\%)\end{array}$ & $\begin{array}{c}\text { Fruit samples with } \\
\text { parasitoids (\%) }\end{array}$ \\
\hline Without releases & 468 & 5 & 1.05 & 3.8 \\
\hline With releases & 5271 & 947 & 16.50 & 27.7 \\
\hline
\end{tabular}




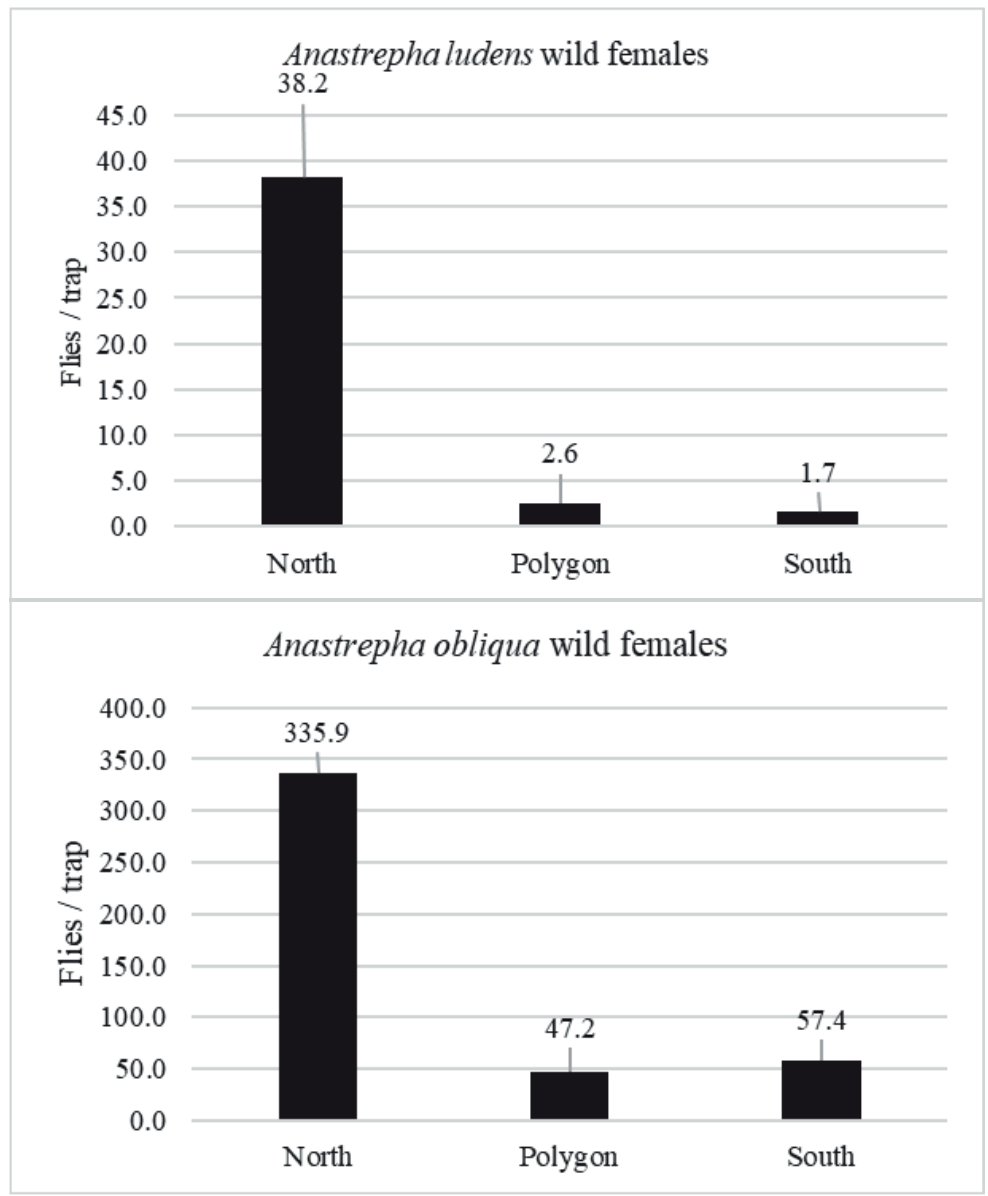

Figure 7. Mean (SE) capture of wild females expressed in flies per trap for A. ludens and A. obliqua in the 2012-13 and 2013-14 seasons within the release polygon and in the traps located north and south of the release polygon.

\subsection{Infested Batches and the Species of Concern}

The differences in abundance observed between the two species - A. ludens and $A$. obliqua - were consistent and in agreement with what was previously reported (Aluja et al. 1996). However, this difference did not match the detection of infested batches of mango in the packing houses: more than $94 \%$ of the infested lots were by $A$. ludens (information provided by the State Committee for Plant Health of Chiapas) (Table 6).

In 2014, Aluja et al. (2014) reported that mango cultivar Ataulfo was not infested by A. obliqua when fruits were still on the trees. Only the fruits known as "mango niño" (baby mango) were infested. These are small fruits of the same cultivar that do not grow as the normal fruits. The Ataulfo cultivar is the one that occupies the largest surface area in Chiapas and represents more than $90 \%$ of mango exports. This 
observation made us conclude that $A$. ludens was the important species to suppress to minimize or prevent fruit infestation. This new knowledge was fortunate as the programme could receive sufficient sterile male $A$. ludens to achieve densities of 800 to 1000 males per ha, reaching sterile: fertile ratios of more than 100:1.

Table 6. Number of infested batches at the packing houses per species and the percent of those infested by Anastrepha ludens

\begin{tabular}{|c|c|c|c|}
\hline Season & A. obliqua & A. ludens & $\%$ A. ludens \\
\hline 2012 & 21 & 390 & 94.9 \\
\hline 2013 & 9 & 401 & 97.8 \\
\hline 2014 & 6 & 236 & 97.5 \\
\hline 2015 & 3 & 241 & 98.8 \\
\hline
\end{tabular}

\section{FROM A RESEARCH PROJECT TO AN ACTION PROGRAMME}

Considering the four seasons of the research project, we were able to verify and validate the effectiveness of the SIT and the ABC for the suppression of populations of these two species of fruit flies. The strategy of establishing a "biological barrier" between the midlands and highlands with high fruit fly populations, and the lowlands, where the largest area planted with commercial mango is located, seemed to be appropriate to reduce fruit fly infestation in mango from $76 \%$ to $91 \%$. Nevertheless, for an action programme, monitoring should be expanded so that the location of this "biological barrier" is dynamic and can be adapted to the situation of the pest. Also, the importance of achieving high sterile to fertile ratios before the start of the mango season should always be kept in mind.

At this stage of the research project, growers were very interested in continuing the releases of sterile insects and parasitoids. They were willing to contribute the needed funds, and to fulfil the requirements to be considered for participation in the National Campaign. It was decided to focus only on $A$. ludens, and the National Campaign offered to provide the programme with 15 million sterile males (Tapachula7 genetic sexing strain) and 5 million $D$. longicaudata for the ABC.

A technical group to follow up the programme was established with participants from the mango growers' union, the State Plant Health Committee, the National Fruit Fly Campaign and ECOSUR (El Colegio de la Frontera Sur, public research centre). This technical group meets every two weeks or weekly, depending on the time of the year. The technical group agreed on the design of a new release polygon of 15000 ha based on the pest situation and the availability of biological material. Releases of sterile flies and parasitoids have not been stopped since then. As an example of this follow-up, the situation for week 25 in 2016 is shown in Fig. 8, with the location of the modified release polygon $(40 \times 3.75 \mathrm{~km})$, the aerial release lines, and the location of the monitoring traps indicating flies captured. 


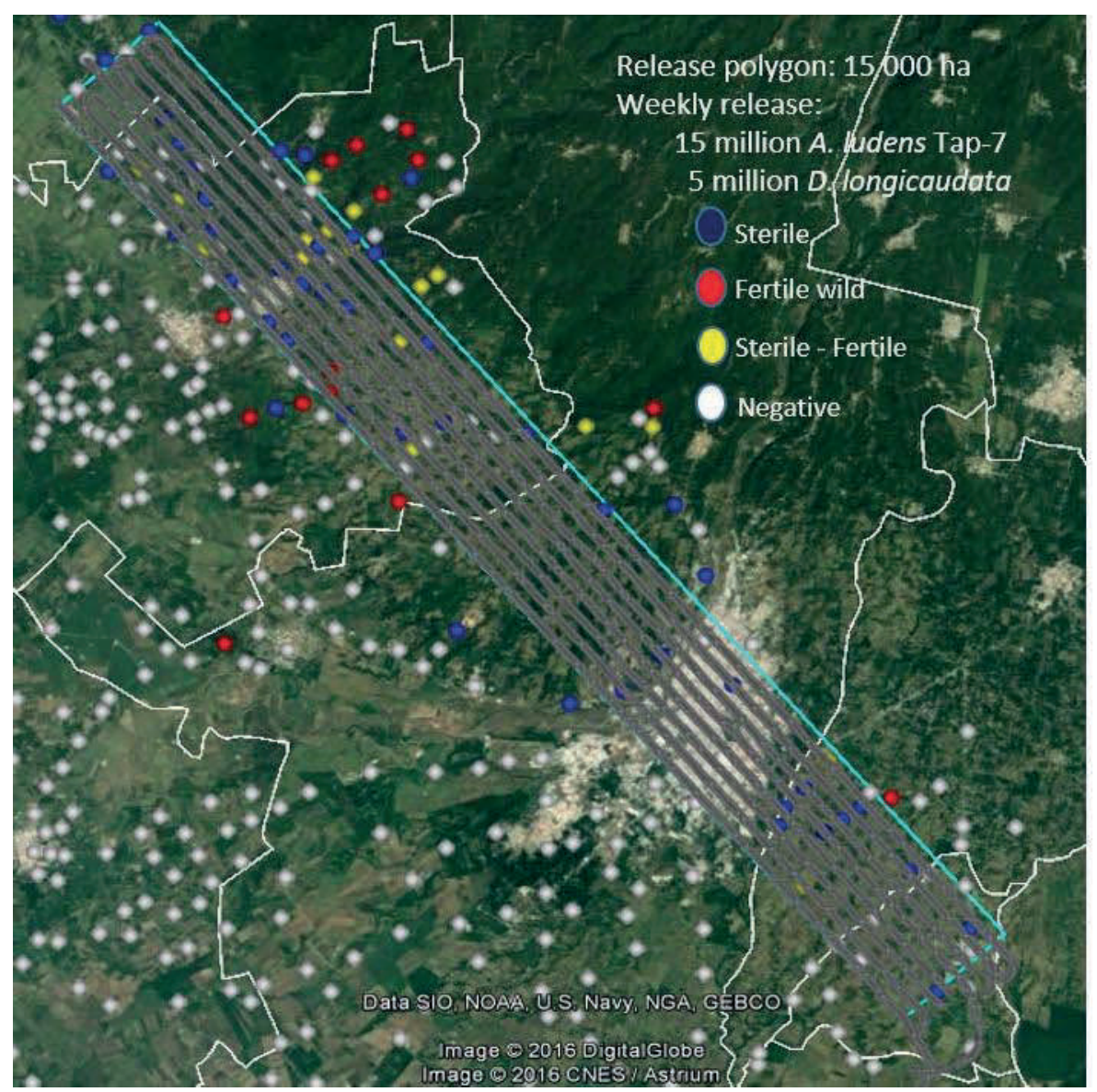

Figure 8. Modified release polygon of the action programme showing flight lines and the location of traps. Colour codes indicate type of trapped flies; sterile -fertile means that both types of flies were captured in the trap; these data correspond to week 25, 2016.

Although there was no immediate suppression effect of sterile flies and parasitoids releases, the continued releases from 2012 to 2017 resulted in a gradual suppression of wild A. ludens populations and as a result the number of infested mango batches detected at the packing houses has been greatly reduced. The number of infested batches per season, and the corresponding index of infested batches per ton of exported mangoes are shown in Fig. 9. These results are encouraging and demonstrate the long-term effects of area-wide integration of the SIT and the ABC. They also show that with good knowledge of the dynamics of fruit fly populations it is feasible to design AW-IPM programmes, integrating the SIT and the ABC in the management of fruit flies under tropical conditions where pest populations are normally high. 
The challenge now is to maintain and refine the releases of sterile flies and parasitoids and assess whether their synergistic effect will further decrease the pest populations, and in the long term minimize or avoid bait insecticide sprays in the region.
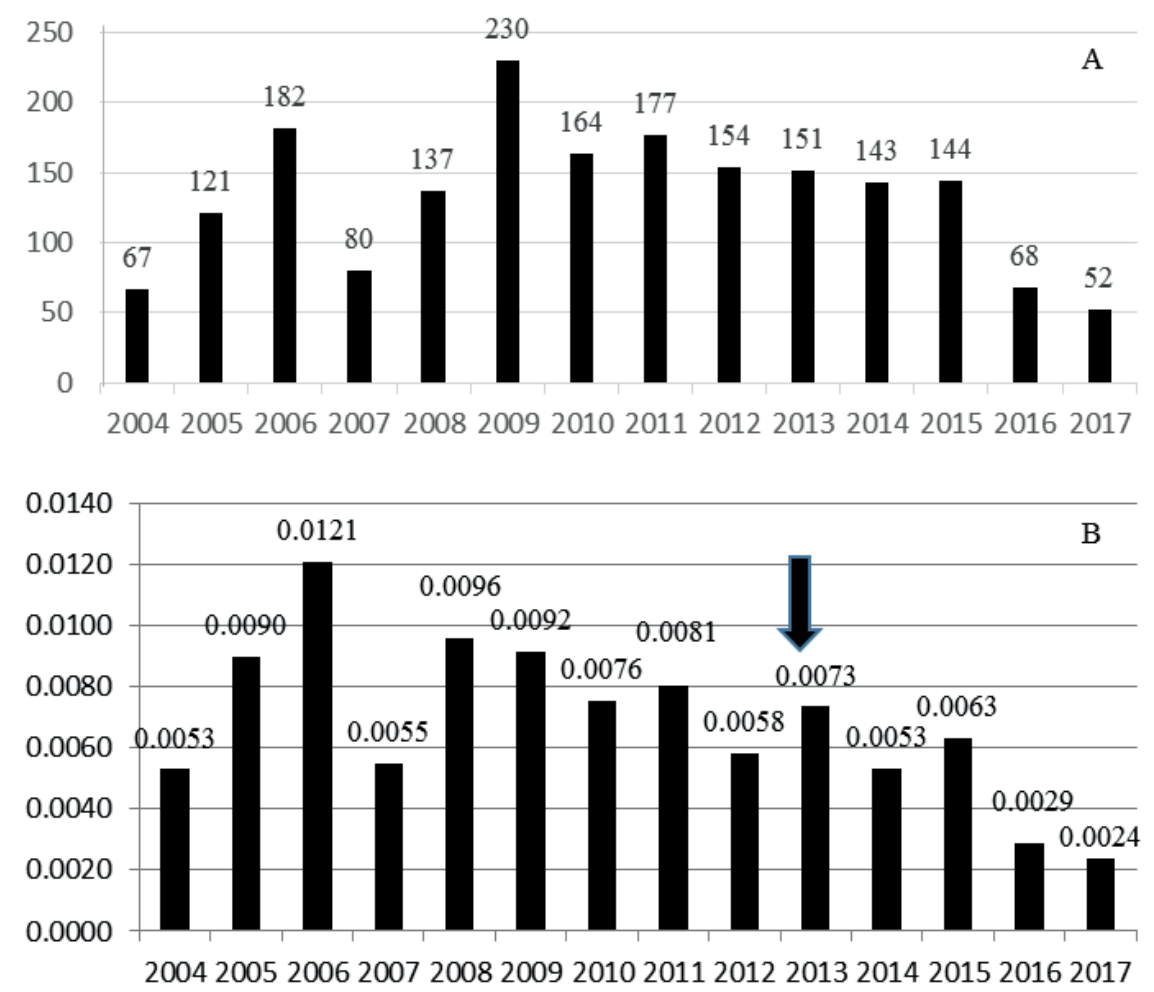

Figure 9. Number of infested batches detected at packing houses per season (A) and index of infested batches per ton of exported mangoes $(B)$. The arrow shows when releases of sterile flies and parasitoids were initiated.

\section{ACKNOWLEDGMENTS}

We thank Ezequiel de León, Reyna Bustamante, Azucena Oropeza, Lucy Tirado, Fredy Gálvez, Rolando Cabrera, and Pedro Leal for technical assistance. The Mexican National Campaign of Fruit Flies (SENASICA, SAGARPA) provided biological material, infrastructure and technical and logistical support. We especially thank the Local Board of Plant Health, the Soconusco Fruit Growers Association, and the State Plant Health Committee of Chiapas for having made possible the transformation of a research project into an action programme. The research project was funded by the SAGARPA-CONACYT sectorial fund to project 163431. 


\section{REFERENCES}

Aluja, M., H. Celedonio-Hurtado, P. Liedo, M. Cabrera, F. Castillo, J. Guillen, and E. Rios. 1996. Seasonal population fluctuations and ecological implications for management of Anastrepha fruit flies (Diptera: Tephritidae) in commercial mango orchards in southern México. Journal of Economic Entomology 89: 654-667.

Aluja, M., J. Arredondo, F. Díaz-Fleischer, A. Birke, J. Rull, J. Niogret, and N. Epsky. 2014. Susceptibility of 15 mango (Sapindales: Anacardiaceae) cultivars to the attack by Anastrepha ludens and Anastrepha obliqua (Dipetera: Tephritidae) and the role of underdeveloped fruit as pest reservoirs: Management implications. Journal of Economic Entomoogy 107: 375-388.

Celedonio-Hurtado, H., M. Aluja, and P. Liedo. 1995. Adult population fluctuations of Anastrepha species (Diptera: Tephritidae) in tropical orchard habitats of Chiapas, Mexico. Environmental Entomology 24: 861-869.

Enkerlin, W. R. 2021. Impact of fruit fly control programmmes using the Sterile Insect Technique, pp. 977-1004. In V.A. Dyck, J. Hendrichs, and A. S. Robinson (eds.), Sterile Insect Technique Principles and practice in Area-Wide Integrated Pest Management. Second Edition. CRC Press, Boca Raton, Florida, USA.

Enkerlin, W., J. M. Gutiérrez-Ruelas, A. Villaseñor-Cortes, E. Cotoc-Roldan, D. Midgarden, E. Lira, J. L. Zavala-López, J. Hendrichs, P. Liedo, and F. J. Trujillo-Arriaga. 2015. Area freedom in Mexico from Mediterranean fruit fly (Diptera: Tephritidae): A review of over 30 years of a successful containment program using an integrated area-wide SIT approach. Florida Entomologist 98: 665-681.

(FAO) Food and Agriculture Organization of the United Nations. 2008. Establishment of areas of low pest prevalence for fruit flies (Tephritidae). International Standard for Phytosanitary Measures (ISPM) No. 30. International Plant Protection Convention. Rome, Italy.

(FAO) Food and Agriculture Organization of the United Nations. 2016. Establishment of pest free areas for fruit flies (Tephritidae). International Standard for Phytosanitary Measures (ISPM) No. 26. International Plant Protection Convention. Rome, Italy.

FAO/IAEA/USDA (Food and Agriculture Organization of the United Nations/International Atomic Energy Agency/United States Department of Agriculture). 2019. Product quality control for sterile mass-reared and released tephritid fruit flies. Version 7.0. International Atomic Energy Agency, Vienna, Austria. 148 pp.

Flores, S., P. Montoya, J. Toledo, W. Enkerlin, and P. Liedo. 2014. Estimation of populations and sterility induced in Anatrepha ludens (Diptera: Tephiritidae) fruit flies. Journal of Economic Entomology 107: 1502-1507.

Flores, S., E. Gómez-Escobar, P. Liedo, J. Toledo, and P. Montoya. 2017. Density estimation and optimal sterile-to-wild ratio to induce sterility in Anastrepha obliqua populations. Entomologia Experimentalis et Applicata 164(3): 284-290.

Hendrichs, J., P. Kenmore, A. S. Robinson, and M. J. B. Vreysen. 2007. Area-wide integrated pest management (AW-IPM): Principles, practice and prospects, pp. 1-31. In M. J. B. Vreysen, A. S. Robinson, and J. Hendrichs (eds.), Area-wide control of insect pests: From research to field implementation. Springer, Dordrecht, The Netherlands.

Hernández, E., A. Escobar, B. Bravo, and P. Montoya. 2010. Chilled packing systems for fruit flies (Diptera: Tephritidae) in the Sterile Insect Technique. Neotropical Entomology 39 (4): 601-607.

Knipling, E. F. 1955. Possibilities of insect control or eradication through the use of sexually sterile males. Journal of Economic Entomology 48: 459-462.

Liedo, P. 2016. Management of fruit flies in Mexico, pp. 695-704. In S. Ekesi, S. A. Mohamed, M. DeMeyer (eds.), Fruit fly research and development in Africa - Towards a sustainable management strategy to improve horticuluture. Springer International Publishing, Switzerland.

Montoya, P. and J. Toledo. 2010. Estrategias de control biológico, pp. 169-182. In P. Montoya, J. Toledo, and E. Hernández (eds.), Moscas de la fruta: Fundamentos y procedimientos para su manejo. SyG Editores, México, DF, México.

Montoya, P., J. Cancino, and L. Ruiz. 2012. Packing of fruit fly parasitoids for augmentative releases. Insects 3: 889-899.

Montoya, P., P. Liedo, B. Benrey, J. Cancino, J. F. Barrera, J. Sivinski, and M. Aluja. 2000. Biological control of Anastrepha spp. (Diptera: Tephritidae) in mango orchards through augmentative releases of Diachasmimorpha longicaudata (Ashmead) (Hymenoptera: Braconidae). Biological Control 18: 216-224. 
Montoya, P., J. Cancino, M. Zenil, G. Santiago, and J. M. Gutiérrez. 2007. The augmentative biological control component in the Mexican campaign against Anastrepha spp. fruit flies, pp. 661670. In M. J. B. Vreysen, A. S. Robinson, and J. Hendrichs (eds.), Area-wide control of insect pests: From research to field implementation. Springer. Dordrecht, The Netherlands. ISBN 978-4020-60588.

Montoya, P., P. López, J. Cruz, F. López, C. Cadena, J. Cancino, P. Liedo. 2017. Effect of Diachasmimorpha longicaudata releases on the native parasitoid guild attacking Anastrepha spp. larvae in disturbed zones of Chiapas, Mexico. BioControl 62: 581-593.

Ramírez y Ramírez, F., R. A. Hernández-Livera, and A. Bello-Rivera. 2019. El Programa nacional de moscas de la fruta en México, pp. 3-20. In P. Montoya, J. Toledo, and E. Hernández (eds.), Moscas de la fruta: Fundamentos y procedimientos para su manejo, 2nd edición. SyG Editores, México, DF, México,

Reyes, J., G. Santiago, and P. Hernández. 2000. The Mexican fruit fly eradication program, pp. 377380. In K. H. Tan (ed.), Area-wide control of fruit flies and other insect pests. Penerbit Universiti Sains Malaysia, Pulau, Pinang, Malaysia.

(SIAP) Servicio de Información Agroalimentaria y Pesquera. 2015. México, D. F., México. 